\title{
Multidisciplinary approach to the diagnosis and management of patients with peripheral arterial disease
}

\section{Craig MWalker ${ }^{1,2}$ \\ Frank T Bunch ${ }^{3}$ \\ Nick G Cavros ${ }^{4}$ \\ Eric J Dippel ${ }^{5}$}

'Cardiovascular Institute of the South, Tulane University School of Medicine, New Orleans, LA, ${ }^{2}$ Louisiana State University School of Medicine, New Orleans, LA, ${ }^{3}$ Cardiology Associates, Mobile, $\mathrm{AL},{ }^{4} \mathrm{Cardiovascular}$ Institute of the South, Lafayette General Medical Center, Lafayette, LA, ${ }^{5}$ Cardiovascular Medicine, PC Genesis Heart Institute, Davenport, IA, USA

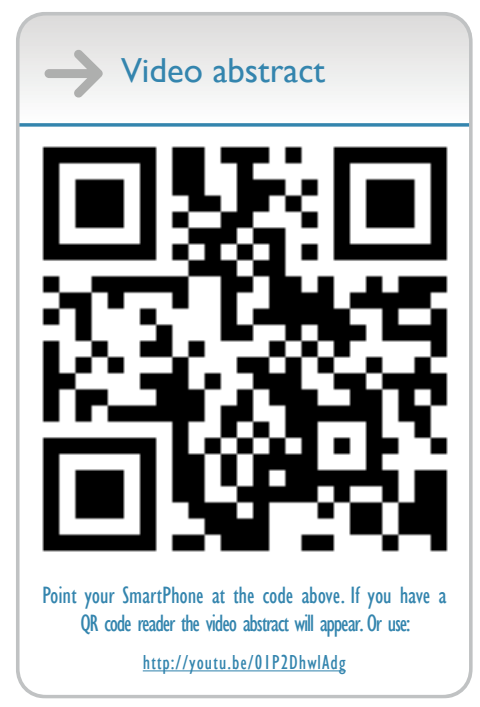

Correspondence: Craig M Walker Cardiovascular Institute of the South, 225 Dunn Street, Houma, LA 70360, USA Tel + I 9858553734

Email craig.walker@cardio.com
This article was published in the following Dove Press journal:

Clinical Interventions in Aging

10 July 2015

Number of times this article has been viewed

\begin{abstract}
Peripheral arterial disease (PAD) is frequently diagnosed after permanent damage has occurred, resulting in a high rate of morbidity, amputation, and loss of life. Early and ongoing diagnosis and treatment is required for this progressive disease. Lifestyle modifications can prevent or delay disease progression and improve symptoms. Limb-sparing endovascular interventions can restore circulation based on appropriate diagnostic testing to pinpoint vascular targets, and intervention must occur as early as possible to ensure optimal clinical outcomes. An algorithm for the diagnosis and management of PAD was developed to enable a collaborative approach between the family practice and primary care physician or internist and various specialists that may include a diabetologist, endocrinologist, smoking cessation expert, hypertension and lipid specialist, endovascular interventionalist, vascular surgeon, orthopedist, neurologist, nurse practitioner, podiatrist, wound healing expert, and/or others. A multidisciplinary team working together has the greatest chance of providing optimal care for the patient with PAD and ensuring ongoing surveillance of the patient's overall health, ultimately resulting in better quality of life and increased longevity for patients with PAD.
\end{abstract}

Keywords: peripheral arterial disease, diagnosis, endovascular intervention

\section{Introduction}

Peripheral arterial disease (PAD) is the progressive stenosis or occlusion of the arteries of the extremities. ${ }^{1}$ The resulting deficiency of oxygenated blood results in degeneration of the vasculature, nerves, and other tissues. PAD can result in intermittent claudication (pain on exertion or impairment walking), pain at rest, and loss of sensation in the extremities, progressing to critical limb ischemia with persistent wounds and infections and ultimately a gangrenous lesion requiring amputation of digits or an extremity. ${ }^{2}$ PAD is associated with a higher risk of coronary artery disease, myocardial infarction, and cerebrovascular disease, ${ }^{3}$ and is a marker for cardiovascular death and disability with a $22 \%$ mortality rate at 4.4 years. ${ }^{4}$ PAD is typically caused by atherosclerosis of the peripheral arteries. Symptoms of this pathology may not be apparent for years, and the majority of individuals with PAD are asymptomatic ${ }^{5}$ or ascribe their symptoms to innocuous causes. Consequently, the majority of cases of PAD are undiagnosed, and greater awareness of early signs and symptoms is needed.

Patients with PAD suffer a double burden of delayed diagnosis of their condition and infrequent use of limb-sparing treatments. PAD often progresses to a point of irreversible damage due to lack of awareness on the part of both patients and health care providers, limited availability of diagnostic tests in some primary care centers, 
and delayed referral for endovascular evaluation. ${ }^{6}$ A 2012 review of Medicare patients who underwent a major amputation for critical limb ischemia $(n=20,464)$, showed that $71 \%$ had no revascularization attempts, and $46 \%$ had no diagnostic angiogram prior to a major amputation. ${ }^{7}$ Another study showed that primary amputation was the first procedure for the treatment of critical limb ischemia in $67 \%$ of Medicare patients. ${ }^{8}$ The progressive, heterogeneous nature of PAD requires ongoing diagnostic testing to ensure optimal clinical outcomes.

The incidence of PAD has grown to epidemic proportions and is expected to increase further due to the continued growth in prevalence of diabetes and the general aging of the US population. Approximately 8-14 million people in the USA and an estimated 202 million people worldwide had PAD as of $2010 .^{9,10}$ More than 1 million people in the USA have lost a limb due to vascular disease, including diabetes, PAD, and critical limb ischemia, ${ }^{11}$ and approximately half the individuals with limb loss due to vascular disease die within 5 years of the amputation. ${ }^{12}$ Up to $85 \%$ of these amputations could have been delayed or prevented through patient education, lifestyle modification, early diagnosis, and endovascular intervention. ${ }^{13-19}$

This paper describes an algorithm for the screening and ongoing diagnosis of PAD by a primary care physician in partnership with a team of specialty health care providers (Figure 1). The goal of this algorithm is early diagnosis, appropriate referrals, and establishment of a multidisciplinary treatment strategy including early angiography, appropriate use of endovascular interventions, and ultimately decreased limb loss, morbidity, and mortality.

\section{Initial screening}

PAD screening should be performed in adults over the age of 50 years with risk factors such as high cholesterol, hypertension, diabetes, smoking, obesity, family history of atherosclerosis, PAD or claudication, neuropathic leg pain, or a non-healing wound or infection on an extremity, in addition to anyone over the age of 70 years. ${ }^{10,20}$ The initial screening for PAD includes an evaluation of the extremities and a detailed medical history (Figure 1A). Claudication occurs in approximately $60 \%$ of individuals with $\mathrm{PAD},{ }^{21}$ and other signs and symptoms of PAD may be present in patients without pain. Critical limb ischemia can occur with or without prior occurrence of less severe symptoms and is present in $5 \%-10 \%$ of patients at the time of PAD diagnosis. ${ }^{3}$ Patients with critical limb ischemia have a 20\% mortality rate in the first year after presentation, adding to the urgency of diagnosis and treatment. ${ }^{22}$ Coronary artery or cerebrovascular disease is present in $40 \%-60 \%$ of patients with PAD. ${ }^{22}$ Consequently, all patients with PAD are highrisk patients.

\section{Lower limb evaluation}

Assess the lower limbs for signs and symptoms of PAD including: leg pain (at rest or on exertion); non-healing ulcers, sores, or infections; hair loss; cool, smooth or shiny skin; muscle atrophy; decreased or absent pulses (feet); and cold or numb toes. ${ }^{21,23}$ Claudication includes pain, ache, or cramp in the buttock, hip, thigh, or calf and, in $10 \%-35 \%$ of PAD patients, occurs only during exercise such as walking and resolves within 10 minutes of resting. ${ }^{3}$ Claudication is atypical in $40 \%-50 \%$ of $\mathrm{PAD}$ patients, such that leg pain does not resolve at rest and/or the pain begins while the patient is at rest. ${ }^{3}$ Comorbidities can influence the experience of leg pain and further complicate diagnosis. ${ }^{24}$

\section{Careful medical history for coronary or carotid artery disease}

Risk factors for coronary artery disease include those for PAD as well as radiation therapy to the chest, physical inactivity, and stress. Intermittent pain, pressure or tightness of the chest, and shortness of breath on exertion are symptoms of coronary artery disease. Risk factors for carotid artery disease include those for PAD as well as physical inactivity and sleep apnea. There are no signs or symptoms of carotid artery disease until a stroke or transient ischemic attack occurs, which causes sudden numbness, weakness, dizziness, severe headache, difficulty speaking, and/or trouble seeing. Carotid auscultation may reveal bruits suggestive of carotid artery disease.

All screened individuals should be provided with education regarding lifestyle modifications to prevent or delay progression of PAD (Table 1). If the patient has signs or symptoms of PAD, then the individual should undergo physiological screening with an endovascular interventionalist or vascular specialist. If the screening evaluation for coronary or carotid artery disease is suggestive, then the patient should be referred to a cardiologist or vascular specialist for further evaluation and treatment.

\section{Physiological screening}

Physiological screening (Figure 1B) should be performed in all patients with any signs or symptoms of PAD and must include an ankle-brachial index (ABI). Clinics with a SensiLase ${ }^{\circledR}$ system may conduct other assessments with the ABI. Clinical sensory testing should also be performed. Detailed descriptions of each assessment are provided in 


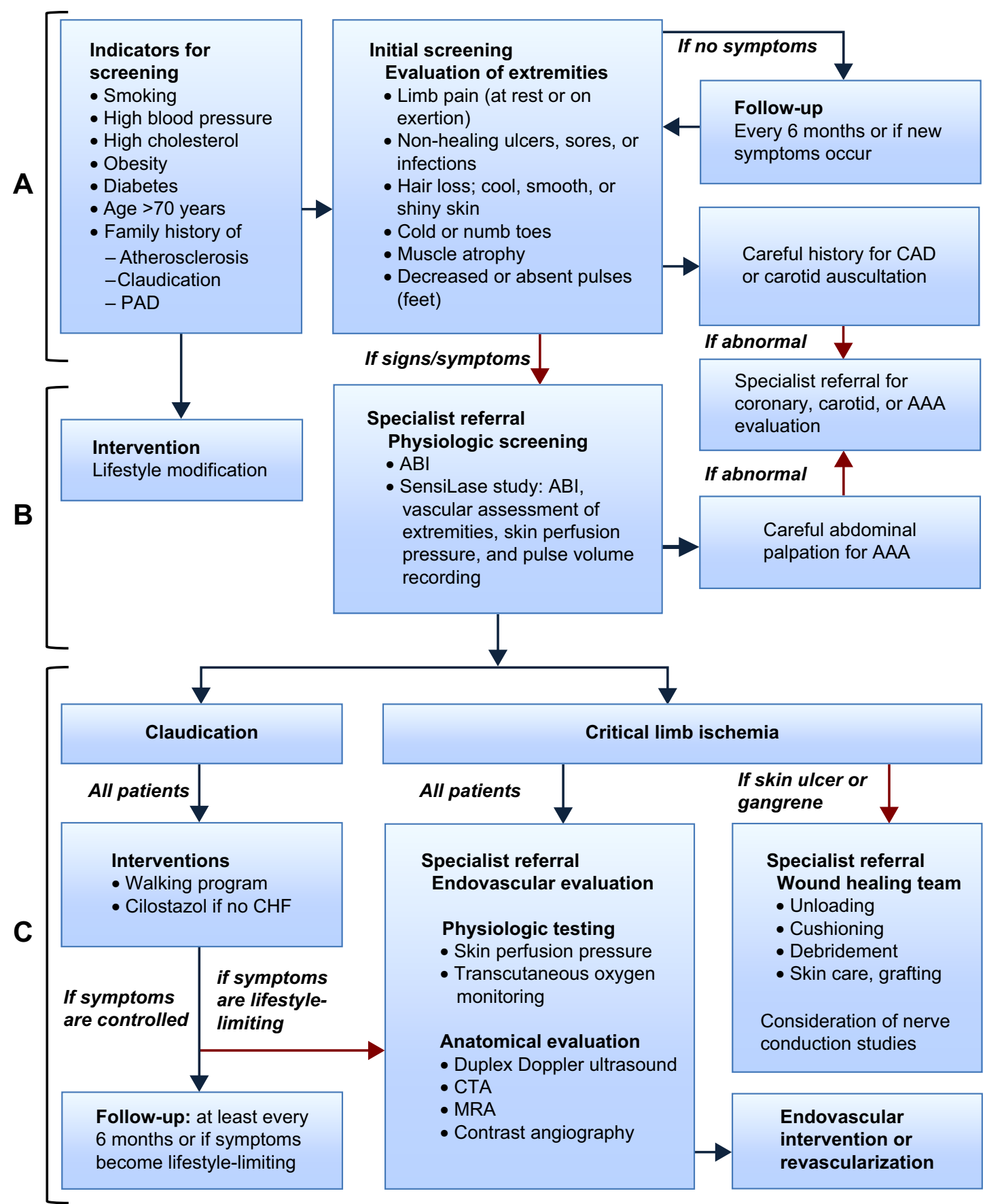

Figure I Algorithm for the diagnosis and management of patients with PAD.

Notes: Scheme shows the flow of patients at risk for PAD (A), with signs or symptoms of PAD (B), and with a diagnosis of PAD (C).

Abbreviations: $A A A$, abdominal aortic aneurysm; $A B I$, ankle-brachial index; $C A D$, coronary artery disease; CHF, congestive heart failure; CTA, computed tomographic angiography; MRA, magnetic resonance angiography; $P A D$, peripheral arterial disease.

Anderson et $\mathrm{al}^{25}$ and a guideline to differential diagnoses for intermittent claudication may be found in the practice guidelines for atherosclerotic occlusive disease of the lower extremities from the Society for Vascular Surgery. ${ }^{5}$

The ABI compares the systolic blood pressure of the ankle with that of the arm both at rest and after exercise. PAD generally produces discrepancies between the blood pressure of the ankles and that of the arms. If an $\mathrm{ABI}$ is 0.9 or less at rest, or greater than 1.3, the patient should be referred to a specialist familiar with endovascular intervention for a complete endovascular evaluation. This test is not reliable in patients with long-term diabetes or advanced renal disease, who may have severely calcified arteries, preventing an accurate result reflective of the disease..$^{26,27}$ The SensiLase study provides an ABI as well as a noninvasive upper and lower extremity vascular assessment including skin perfusion 
Table I Lifestyle modifications

Cessation of smoking

Improved control of diabetes

Improved control of hypertension

Improved control of lipids

Weight loss/management

Regular physical activity and exercise

pressure and pulse volume recording. ${ }^{6}$ Quantitative clinical sensory testing assesses nerve sensitivity with regard to hot, cold, and vibration, quantifying abnormalities in pain and sensory pathways that can suggest deafferentation and/or sensitization. ${ }^{28}$

Careful abdominal palpation and auscultation should be performed for abdominal aortic aneurysm. Symptoms of an abdominal aortic aneurysm include abdominal or back pain as well as a pulsating feeling near the navel. Palpation of the abdomen for a pulsating bulge may reveal an aortic aneurysm, and auscultation may reveal a bruit. Smoking and family history are the most common risk factors for abdominal aortic aneurysm and a history of vasculitis is a strong predictor. If the evaluation is suggestive of abdominal aortic aneurysm, then the patient is referred to a cardiologist or vascular specialist for further evaluation and treatment.

If physiological screening results are not suggestive and there are no symptoms, the individual may be re-evaluated every 6 months or sooner if symptoms arise. If the patient has claudication but other tests are not suggestive, then a walking program or supervised exercise program and antiplatelet medication may be added to the lifestyle modifications (Figure 1C). Many individuals require an organized program or trainer while others do well with a timer or chart. In patients diagnosed with PAD, aspirin (starting at 75-100 mg once daily) or other antiplatelet medications such as clopidogrel (75 mg once daily) may be prescribed, if not contraindicated, for preventing stroke, myocardial infarction, and death. In patients who do not have congestive heart failure, cilostazol, an antiplatelet and vasodilator agent, may be prescribed. ${ }^{29}$ These individuals should be followed on a 6-monthly basis.

If the patient has symptoms that are lifestyle-limiting or the results of any evaluations are suggestive, then the individual is considered to be at high risk for critical limb ischemia and should undergo physiologic testing with an endovascular interventionalist or vascular specialist. Early intervention with endovascular techniques can provide functional improvement and increase quality of life. ${ }^{2}$ The combination of an exercise program and endovascular intervention has shown better results than either of these alone in patients with intermittent claudication. . $^{2,30}$

\section{Endovascular evaluation}

Endovascular evaluation should be performed when claudication or other symptoms of PAD are lifestyle-limiting or critical limb ischemia is suspected (Figure 1C). Endovascular evaluation includes physiological testing (skin perfusion pressure and transcutaneous oxygen monitoring) as well as anatomic evaluation (duplex Doppler ultrasound, various types of angiography). ${ }^{9,21,23,25}$ These assessments provide verification of PAD, location of arteries that may be blocked, and the level of severity of the disease. ${ }^{5,26}$ In a study of over one million Medicare inpatients with critical limb ischemia, an angiogram alone was found to reduce the odds of amputation by $90 \%{ }^{31}$ The appropriate type of angiogram can pinpoint the vascular targets for procedural treatment. ${ }^{32}$ Selection of the imaging study is based on availability and expertise in the local region, patient characteristics, and potential treatment options for a given patient. Generally, the least invasive tests are conducted first. The results of these tests will direct the intervention(s) most appropriate for the patient. Referral to a specialist familiar with endovascular intervention should happen prior to these tests, allowing the specialist to conduct and interpret the tests appropriate to the individual. The results of the tests should be shared with the multidisciplinary team, and a coordinated treatment and surveillance plan should be developed.

\section{Duplex Doppler ultrasound}

Duplex Doppler ultrasound is the most important evaluation for confirming a diagnosis of PAD and assessing the severity of arterial stenosis. It combines hemodynamic evaluation with imaging and provides information on pressure and flow. ${ }^{5,25}$

\section{Magnetic resonance angiography}

Magnetic resonance angiography and computed tomographic angiography are imaging studies, and one of these is the next step after duplex Doppler ultrasound in planning an intervention for PAD. Magnetic resonance angiography is prohibited in patients with pacemakers or numerous other implantable devices. . $^{5,25}$

\section{Computed tomographic angiography}

Computed tomographic angiography is an imaging study considered to be the next step after duplex Doppler ultrasound in planning an intervention for PAD. Generally, image clarity is improved over magnetic resonance angiography; however, 
the contrast material interacts with arterial calcification, producing artifacts that can interfere with image quality. In addition, an allergy to the contrast material may be present, and this must be ruled out prior to use. Consequently, contrast angiography may be unsuitable in some patients. ${ }^{5,25}$

\section{Contrast or catheter angiography}

This is considered the gold standard for evaluating arterial anatomy due to the superior image quality. Although more invasive, catheter angiography is essential for revascularization planning. However, similar issues exist with regard to injecting contrast material, and arterial access site complications may present a substantial risk to some patients. ${ }^{5,25}$ Angiographic testing may not be considered in planning the care of the patient with PAD by some practitioners due to the risk of contrast-induced nephropathy caused by iodinated contrast. Contrast-induced nephropathy is defined as an increase of $25 \%$ or more, or an absolute increase of $0.5 \mathrm{mg} / \mathrm{dL}$ or more, in serum creatinine from the baseline value at 48-72 hours following exposure to contrast medium. ${ }^{33}$ Mehran and Nikolsky developed a simple risk scoring system for evaluating the risk of contrast-induced nephropathy that can help identify when alternatives to contrast medium should be used. ${ }^{34}$ An alternative to iodinated contrast is carbon dioxide for angiographic assessment and interventional treatment of PAD. With the use of a commercially available system, carbon dioxide provides high quality imaging of the peripheral vasculature. Gaseous carbon dioxide displaces the blood, then is rapidly dissolved in the blood and excreted within several breaths via the lungs. Since there is no increased risk for contrastinduced nephropathy without the use of iodinated contrast, angiography using carbon dioxide is a viable option for patients with PAD. ${ }^{35}$

\section{Skin perfusion pressure test}

The skin perfusion pressure test measures tissue perfusion (microcirculation) and reflects the metabolic state of the lower limbs for diagnosis of critical limb ischemia as well as giving an indication of wound healing and severity of PAD. A skin perfusion pressure measurement greater than $40 \mathrm{mmHg}$ predicts sufficient blood flow for wound healing. ${ }^{36}$

\section{Transcutaneous oxygen monitoring}

This noninvasive test measures tissue perfusion (microcirculation), reflects the metabolic state of the lower limbs for diagnosis of critical limb ischemia, and is a predictor of wound healing. Generally, a transcutaneous oxygen measurement over $30 \mathrm{mmHg}$ predicts sufficient blood flow for wound healing. The occasional patient will experience sufficient pain during this test as to prevent completion of the test. ${ }^{36}$

\section{Podiatry/wound healing}

Patients with non-healing ulcers or infections on their feet should be referred to a podiatrist or wound healing team for complete foot care and regular follow-up (Figure 1C). Skin ulcers often go undetected in individuals with a loss of feeling in their feet and limited flexibility to observe foot health. Patient education, regular foot care, and checkups have been shown to save limbs. The Comprehensive Diabetic Foot Exam program of the American Diabetes Association screens diabetic patients with no obvious wounds, which allows prevention programs and intervention to occur earlier. $^{37}$

Wounds may require unloading, cushioning, debridement, and skin grafting by a wound care team or podiatrist. Nerve conduction studies may be useful. Non-healing wounds on an extremity may be treated with a prolonged duration of antibiotics and/or hyperbaric therapy; however, these therapies are only effective if the circulation of the injured extremity is sufficient. Thus, knowledge of circulatory status is mandatory for treatment of ulcers and non-healing wounds, and yet some patients are treated with these therapies with no assessment of the foot. ${ }^{38}$ A multidisciplinary team approach to foot and wound care will ensure that wounds are prevented, wounds are treated properly, and blood flow to and within the foot is monitored. A significant decrease in amputation rates will rely on a team approach. ${ }^{39}$

\section{Management of PAD}

Recent advances in endovascular interventions have provided numerous limb-sparing options for the treatment of PAD. Improvements in technique and equipment have expanded the use of endovascular interventions to more severe patients as well as less severe cases. ${ }^{40}$ However, utilization of these interventions varies considerably according to region and the health of the individual. ${ }^{7}$ Comorbid conditions, such as arthritis, spinal disease, neuropathy, diabetes, and spinal stenosis can impact the presentation of PAD and influence the selection of treatment. ${ }^{24}$ Patients with comorbidities that prevent them from being candidates for surgical procedures may be able to undergo endovascular interventions, and yet these limb-sparing procedures may be overlooked. Patients with decreased mobility at the time of diagnosis may also be overlooked for limb-sparing interventions.

Critical limb ischemia and lifestyle-limiting claudication can be treated with an endovascular intervention such as angioplasty to open the artery or with vascular surgery to bypass the 
arterial blockage. In some patients, a combination of endovascular and surgical interventions may be beneficial. Angioplasty includes the use of a catheter and balloon to expand a blocked or narrow artery; placement of stents, which may be medicated, within the artery; bypass grafting surgery to shunt blood around the blockage using an artery from elsewhere in the patient's body; and atherectomy to reduce the plaque build-up within the artery using a cutting device or laser. Both percutaneous transluminal intervention and bypass surgery have shown a limb salvage rate of $80 \%$ at 3 years. ${ }^{41}$

A multidisciplinary team provides an optimal approach to the diagnosis and treatment of PAD and the prevention of unnecessary amputations. The PAD management team may include the family practice and primary care physician, an internist, diabetologist, endocrinologist, hypertension and lipid specialist, endovascular interventionalist, vascular surgeon, orthopedist, neurologist, nurse practitioner, podiatrist, wound healing expert, smoking cessation expert, and others. Each patient has a unique combination of symptoms, comorbidities, genetics, and vasculature, and over time comorbidities change, the patient ages, and the disease progresses, revealing new symptoms and pathophysiologies. Prompt referral and due consideration of the particular details of a given patient will encourage appropriate and effective management with the greatest chance of longevity, quality of life, and prevention of unnecessary amputations.

\section{Acknowledgments}

The authors acknowledge the collaborative support of the Horizons International Peripheral Group and the contributions of Leslie Todd, Eminence Clinical Research Inc, to this manuscript.

\section{Disclosure}

Funding for the coordination of this manuscript and assistance with medical writing was provided by Covidien. This research was presented in part at the New Cardiovascular Horizons Annual Conference, New Orleans, LA, USA, June 5-7, 2013. The authors report no other conflicts of interest.

\section{References}

1. Hiatt WR, Goldstone J, Smith SC Jr, et al. Atherosclerotic Peripheral Vascular Disease Symposium II: nomenclature for vascular diseases. Circulation. 2008;118:2826-2829.

2. Jones WS, Schmit KM, Vemulapalli S, et al. Treatment strategies for patients with peripheral artery disease. Comparative Effectiveness Review No. 118. (Prepared by the Duke Evidence-based Practice Center under Contract No. 290-2007-10066-I.) AHRQ Publication No. 13-EHC090-EF. Rockville, MD, USA: Agency for Healthcare Research and Quality; May 2013. Available from: www.effectivehealthcare.ahrq. gov/reports/final.cfm. Accessed April 21, 2015.
3. Hirsch AT, Haskal ZJ, Hertzer NR, et al. ACC/AHA 2005 practice guidelines for the management of patients with peripheral arterial disease (lower extremity, renal, mesenteric, and abdominal aortic). Circulation. 2006;113:e463-e654.

4. Pande RL, Perlstein TS, Beckman JA, Creager MA. Secondary prevention and mortality in peripheral artery disease: National Health and Nutrition Examination Study, 1999 to 2004. Circulation. 2011;124:17-23.

5. Society for Vascular Surgery Lower Extremity Guidelines Writing Group; Conte MS, Pomposelli FB, Clair DG, et al. Society for Vascular Surgery practice guidelines for atherosclerotic occlusive disease of the lower extremities: management of asymptomatic disease and claudication. J Vasc Surg. 2015;61(3 Suppl):2S-41S.

6. Serena T. SensiLase studycast system: a platform for critical limb diagnostics and electronic referral program. Adv Wound Care (New Rochelle). 2012;1:142-145.

7. Goodney PP, Travis LL, Nallamothu BK, et al. Variation in the use of lower extremity vascular procedures for critical limb ischemia. Circ Cardiovasc Qual Outcomes. 2012;5:94-102.

8. Allie DE, Hebert CJ, Lirtzman MD, et al. Critical limb ischemia: a global epidemic. A critical analysis of current treatment unmasks the clinical and economic costs of CLI. Euro Intervention. 2005;1:60-69.

9. Roger VL, Go AS, Lloyd-Jones DM, et al. Heart Disease and Stroke Statistics. 2011 update: a report from the American Heart Association. Circulation. 2011;123:e18-e209.

10. Fowkes FG, Rudan D, Rudan I, et al. Comparison of global estimates of prevalence and risk factors for peripheral artery disease in 2000 and 2010: a systematic review and analysis. Lancet. 2013;382:1329-1340.

11. Ziegler-Graham K, MacKenzie EJ, Ephraim PL, Travison TG, Brookmeyer R. Estimating the prevalence of limb loss in the United States: 2005 to 2050. Arch Phys Med Rehabil. 2008;89:422-429.

12. Robbins JM, Strauss G, Aron D, Long J, Kuba J, Kaplan Y. Mortality rates and diabetic foot ulcers. $J$ Am Podiatr Med Assoc. 2008;98: 489-493.

13. Frykberg RG. Diabetic foot ulcers: pathogenesis and management. Am Fam Phys. 2002;66:1655-1662.

14. Malone JM, Snyder M, Anderson G, Bernhard VM, Holloway GA, Bunt TJ. Prevention of amputation by diabetic education. Am J Surg. 1989;158: $520-524$.

15. Edmonds M. Diabetic foot ulcers: practical treatment recommendations. Drugs. 2006;66:913-929.

16. Sanders LJ, Robbins JM, Edmonds ME. History of the team approach to amputation prevention: pioneers and milestones. J Vasc Surg. 2010; 52(3 Suppl):3S-16S.

17. Ortegon MM, Redekop WK, Niessen LW. Cost-effectiveness of prevention and treatment of the diabetic foot. Diabetes Care. 2004;27: 901-907.

18. Centers for Disease Control and Prevention. National Diabetes Fact Sheet: National Estimates and General Information on Diabetes and Prediabetes in the United States, 2011. Available from: http://www.cdc. gov/diabetes/pubs/pdf/ndfs_2011.pdf. Accessed August 27, 2014.

19. Driver VR, Madsen J, Goodman RA. Reducing amputation rates in patients with diabetes at a military medical center: the limb preservation service model. Diabetes Care. 2005;28:248-253.

20. Allison MA, Ho E, Denenberg JO, et al. Ethnic-specific prevalence of peripheral arterial disease in the United States. Am JPrevent Med. 2007;32: 328-333.

21. Creager MA, Loscalzo J. Vascular diseases of the extremities. In: Fauci AS, Braunwald E, Kasper DL, et al, editors. Harrison's Principles of Internal Medicine. 17th ed. New York, NY, USA: McGraw Hill; 2008.

22. Norgren L, Hiatt WR, Dormandy JA, Nehler MR, Harris KA, Fowkes FGR; on behalf of the TASC II Working Group. Inter-Society Consensus for the Management of Peripheral Arterial Disease (TASC II). J Vasc Surg. 2007;45:1 Suppl S:5A-67A.

23. Rooke TW, Wennberg PW. Diagnosis and management of diseases of the peripheral arteries and veins. In: Walsh RA, Simon DI, Hoit BD, et al, editors. Hurst's The Heart. 12th ed. New York, NY, USA: McGraw Hill; 2007. 
24. McDermott MM, Greenland P, Liu K, et al. Leg symptoms in peripheral arterial disease: associated clinical characteristics and functional impairment. JAMA. 2001;286:1599-1606.

25. Anderson JL, Halperin JL, Albert NM, et al. Management of patients with peripheral artery disease (Compilation of 2005 and 2011 ACCF/ AHA Guideline Recommendations): a report of the American College of Cardiology Foundation/American Heart Association Task Force on Practice Guidelines. Circulation. 2013;127:1425-1443.

26. Cao P, Eckstein HH, De Rango P, et al. Chapter II: Diagnostic methods. Eur J Vasc Endovasc Surg. 2011;42 Suppl 2:S13-S32.

27. Aboyans V, Criqui MH, Abraham P, et al. Measurement and interpretation of the ankle-brachial index: a scientific statement from the American Heart Association. Circulation. 2012;126:2890-2909.

28. Lang PM, Schober GM, Rolke R, et al. Sensory neuropathy and signs of central sensitization in patients with peripheral arterial disease. Pain. 2006;124:190-200.

29. Reilly MP, Mohler ER, 3rd. Cilostazol: treatment of intermittent claudication. Ann Pharmacother. 2001;35:48-56.

30. Frans FA, Bipat S, Reekers JA, et al. Systematic review of exercise training or percutaneous transluminal angioplasty for intermittent claudication. Br J Surg. 2012;99:16-28.

31. Henry AJ, Hevelone ND, Belkin M, Nguyen LL. Socioeconomic and hospital-related predictors of amputation for critical limb ischemia. J Vasc Surg. 2011;53:330-339.

32. Palena LM, Brocco E, Manzi M. The clinical utility of below-the-ankle angioplasty using "transmetatarsal artery access" in complex cases of CLI. Catheter Cardiovasc Interv. 2014;83:123-129.

33. Yamada $\mathrm{T}$, Ohta $\mathrm{T}$, Ishibashi $\mathrm{H}$, et al. Clinical reliability and utility of skin perfusion pressure measurement in ischemic limbs - comparison with other noninvasive diagnostic methods. 2008;47:318-323.
34. Mehran R, Nikolsky E. Contrast-induced nephropathy: definition, epidemiology, and patients at risk. Kidney Int Suppl. 2006;100:S11-S15.

35. Mehran R, Aymong ED, Nikolsky E, et al. A simple risk score for prediction of contrast-induced nephropathy after percutaneous coronary intervention development and initial validation. J Am Coll Cardiol. 2004;44: 1393-1399.

36. Micari A, Sbarzaglia P, Meeks ME, et al. New imaging modalities in peripheral interventions. Eur Heart J Suppl. 2015;17 Suppl A: A18-A22.

37. Boulton AJ, Armstrong DG, Albert SF, et al. Comprehensive foot examination and risk assessment: A report of the Task Force of the Foot Care Interest Group of the American Diabetes Association, with endorsement by the American Association of Clinical Endocrinologists. Diabetes Care. 2008;31:1679-1685.

38. Yamada T, Onishi K, Utsunomiya M, Nakamura M. Our treatment strategy for critical limb ischemia. Int J Vasc Med. 2013;2013:437471.

39. Alavi A, Sibbald RG, Mayer D, et al. Diabetic foot ulcers: Part I. Pathophysiology and prevention. J Am Acad Dermatol. 2014;70:1. e1-e18.

40. Jaff MR, Cahill KE, Yu AP, Birnbaum HG, Engelhart LM. Clinical outcomes and medical care costs among Medicare beneficiaries receiving therapy for peripheral arterial disease. Ann Vasc Surg. 2010;24: 577-587.

41. Schamp KB, Meerwaldt R, Reijnen MM, Geelkerken RH, Zeebregts CJ. The ongoing battle between infrapopliteal angioplasty and bypass surgery for critical limb ischemia. Ann Vasc Surg. 2012;26:1145-1153.
Clinical Interventions in Aging

\section{Publish your work in this journal}

Clinical Interventions in Aging is an international, peer-reviewed journal focusing on evidence-based reports on the value or lack thereof of treatments intended to prevent or delay the onset of maladaptive correlates of aging in human beings. This journal is indexed on PubMed Central, MedLine,

\section{Dovepress}

CAS, Scopus and the Elsevier Bibliographic databases. The manuscript management system is completely online and includes a very quick and fair peer-review system, which is all easy to use. Visit http://www.dovepress. com/testimonials.php to read real quotes from published authors. 